\title{
Clinical Utility of Reticulocyte Hemoglobin Equivalent in Diagnosing Iron Deficiency Anemia
}

\author{
Kyoung-Jin Park ${ }^{1 \oplus}$ and Moon Jung Kim ${ }^{2 \oplus}$ \\ ${ }^{1}$ Department of Laboratory Medicine \& Genetics, Samsung Changwon Hospital, Sungkyunkwan University School of Medicine, \\ Changwon; 2Department of Laboratory Medicine, Myongji Hospital, Hanyang University College of Medicine, Goyang, Korea
}

\section{Corresponding author:}

Kyoung-Jin Park

Department of Laboratory Medicine \& Genetics, Samsung Changwon Hospital, Sungkyunkwan University School of Medicine, 158 Paryong-ro, Masanhoewon-gu, Changwon 51353, Korea

Tel +82-55-233-6099

E-mail unmar.park@samsung.com

Received: May 13, 2021 Revised: June 30, 2021

Accepted: July 1, 2021
This is an Open Access article distributed under the terms of the Creative Commons Attribution Non-Commercial License (http://creativecommons.org/licenses/ by-nc/4.0) which permits unrestricted non-commercial use, distribution, and reproduction in any medium, provided the original work is properly cited.
Background: Iron deficiency anemia (IDA) is one of the major global public health problems. Reticulocyte hemoglobin ( $\mathrm{Hb}$ ) equivalent (Ret-He) has been proposed as an early index for IDA. However, little information is available regarding the Ret-He in Korean patients with IDA. We aimed to investigate the clinical utility of Ret-He as a diagnostic index in Korean patients with IDA. Methods: Laboratory data, including complete blood count and iron metabolism markers, were retrospectively reviewed. In total, 507 individuals were categorized into four groups based on $\mathrm{Hb}$ and iron index: iron deficiency (ID, $n=21), I D A(n=254)$, non-IDA ( $n=150)$, and healthy control (HC, $\mathrm{n}=82$ ). Receiver operating characteristic analysis was performed to evaluate the diagnostic power of Ret-He.

Results: The Ret-He levels from the ID and IDA groups were significantly lower than those from the non-IDA and HC groups ( $P$-value $<0.0001$; median Ret-He: 32.2 pg for ID; 29.7 pg for IDA; 33.9 pg for non-IDA; and 34.5 pg for $\mathrm{HC}$ ). The area under the curve of Ret-He was 0.851 at a cutoff of $32.3 \mathrm{pg}$, by which IDA was discriminated from HC (sensitivity of $72 \%$ and specificity of 90\%).

Conclusions: This study suggests that Ret-He could be an alternative hematologic index for the diagnosis of IDA. Further prospective clinical studies are warranted to validate the clinical utility of Ret-He and to integrate it into the diagnostic algorithm for IDA.

(Lab Med Qual Assur 2021;43:138-142)

Key Words Reticulocyte hemoglobin equivalent, Ferritina, Iron-deficiency anemia, Anemia, Korean

\section{서론}

빈혈은 세계 인구의 3 분의 1 에서 관찰될 정도로 유병률이 높 으며, 이 중 절반은 철결핍으로 인해 발생한다[1]. 철결핍성빈혈 (iron deficiency anemia)은 성장지연, 행동장애, 인지기능 저하, 면역기능 저하와 관련되어 있으며, 특히 종양 환자에서 치명률을 증가시키므로 조기진단이 중요하다[1].

철결핍성빈혈의 진단에서 신뢰도가 높은 검사법은 골수생검을
통한 철염색(Prussian blue staining)이지만, 침습성과 높은 검사 비용으로 인해 철결핍성빈혈의 진단을 위한 일상적인 검사로 권장 하지 않는다. 주로 평균적혈구용적(mean corpuscular volume) 를 포함한 적혈구지수와 혈청 페리틴(serum ferritin), 혈청 철 (serum iron), 총 철결합능(total iron binding capacity), 트랜 스페린(transferrin), 철포화백분율(transferrin saturation) 등을 검사하며, 이 중 혈청 페리틴을 체내 저장철(iron storage) 결핍의 gold standard로 간주한다. 
하지만 혈청 페리틴은 급성기반응물질(acute phase reactant) 중 하나로 감염, 염증, 간질환, 만성신질환, 악성종양 등에서 증 가할 수 있어 철결핍성빈혈의 진단을 위한 이상적인 검사법이라 고 할 수 없다. 또한 철결핍과 만성질환빈혈(anemia of chronic disease)이 동반되는 경우에는 혈청 페리틴 외 다른 검사결과와 환자의 임상양상 등을 고려한 종합적인 판단이 필요하다.

여러 연구에서 망상적혈구혈색소치(reticulocyte hemoglobin equivalent 또는 reticulocyte hemoglobin content)가 철 결핍성빈혈의 진단에 유용한 검사법으로 보고되고 있다[2-4]. 망상적혈구혈색소치는 망상적혈구 내 혈색소에 대한 측정치 (hemoglobinization)로 새로 생성된 적혈구의 질(quality)에 대 한 정보를 제공한다. 저장철이 감소된 상태에서 망상적혈구혈색소 치는 혈색소보다 일찍 변하기 때문에, 철결핍 상태의 적혈구조혈 에 대한 조기 표지자로 활용될 수 있다. 유아, 소아, 혈액공여자, 임 산부, 혈액투석을 받는 만성신질환자, 지역사회폐렴, 종양 환자에 서 철결핍성빈혈의 진단 시 망상적혈구혈색소치의 유용성이 보고 되었다[5-10].

철결핍성빈혈의 진단을 위한 망상적혈구혈색소치의 임계치는 환자군의 특성에 따라 다양하게 보고된 바 있다[4,6,9,10]. 특정 대상군에서 철결핍성빈혈을 진단하기 위한 망상적혈구혈색소치 의 임계치 설정이 권장되고 있지만, 국내에서 한국인을 대상으로 시행한 임계치 연구는 없다. 이에 본 연구에서는 철결핍성빈혈을 진단하기 위한 망상적혈구혈색소치의 임계치를 설정하고, 임상적 유용성을 평가하고자 한다.

\section{재료 및 방법}

2020년 5월부터 2020년 12월까지 명지병원 건강검진센터 방 문자 3,115 명과 철결핍 또는 빈혈 소견을 보인 성인 환자 425 명(나이 중앙값 70 세)의 검사실 데이터를 후향적으로 획득하였 다. 모든 대상자에서 전혈구검사, 신기능검사, 간기능검사, 혈 청 철, 페리틴 및 철포화백분율검사 결과를 리뷰하였다. 전혈 구 및 망상적혈구혈색소치 검사는 Sysmex XN-20 (Sysmex, Kobe, Japan)에서 시행되었으며, 간기능검사, 신기능검사 및 혈 청 철, 페리틴 및 철포화백분율검사는 ADVIA Chemistry XPT (Siemens, Erlangen, Germany)에서 시행되었다. 본 연구는 명 지병원 임상시험심사위원회(institutional review board)에서 승인을 받은 후 시행하였다(IRB no., 2020-12-005).

환자군 425 명은 빈혈과 철결핍 상태에 따라 다음과 같이 구 분하였다[9] (Table 1). 철결핍군(iron deficiency; 혈색 소: $\geq 13 \mathrm{~g} / \mathrm{dL}$ [남자], $\geq 11 \mathrm{~g} / \mathrm{dL}$ [여자], 철: $<65 \mu \mathrm{g} / \mathrm{dL}$ [남자], $<50 \mu \mathrm{g} / \mathrm{dL}$ [여자], 페리틴: $<12 \mathrm{ng} / \mathrm{mL}$ 을 모두 충족하는 경우; $\mathrm{n}=21$ ), 철결핍성빈혈군(혈색소: $<13 \mathrm{~g} / \mathrm{dL}$ [남자], $<11 \mathrm{~g} / \mathrm{dL}$ [여자], 철: $<65 \mu \mathrm{g} / \mathrm{dL}$ [남자], $<50 \mu \mathrm{g} / \mathrm{dL}$ [여자], 페리틴: $<22 \mathrm{ng} / \mathrm{mL}$, 철포 화백분율 $<20 \%$ 를 모두 충족하는 경우 또는 혈색소: $<13 \mathrm{~g} / \mathrm{dL}$ [남 자], $<11 \mathrm{~g} / \mathrm{dL}$ [여자], 철: $<65 \mu \mathrm{g} / \mathrm{dL}$ [남자], $<50 \mu \mathrm{g} / \mathrm{dL}$ [여자], 페 리틴: $<12 \mathrm{ng} / \mathrm{mL}$ 를 모두 충족하는 경우; $\mathrm{n}=254$ ), 비철결핍성빈혈 군(혈색소: $<13 \mathrm{~g} / \mathrm{dL}[$ 남자], $<11 \mathrm{~g} / \mathrm{dL}[$ 여자], 철: $\geq 65 \mu \mathrm{g} / \mathrm{dL}[$ 남자], $\geq 50 \mu \mathrm{g} / \mathrm{dL}[$ 여자], 페리틴: $\geq 22 \mathrm{ng} / \mathrm{mL} ; \mathrm{n}=150$ )으로 분류하였

Table 1. Demographics and laboratory findings of study population

\begin{tabular}{|c|c|c|c|c|c|}
\hline Characteristic & Control $(n=82)$ & ID $(n=21)$ & IDA $(n=254)$ & Non-IDA $(n=150)$ & $P$-value \\
\hline Age (yr) & $51(20-80)$ & $54(22-80)$ & $70(22-80)$ & $65(20-80)$ & $<0.0001$ \\
\hline Sex & & & & & 0.0670 \\
\hline Male & 47 & 8 & 140 & 81 & \\
\hline Female & 38 & 13 & 114 & 69 & \\
\hline $\mathrm{Hb}(\mathrm{g} / \mathrm{dL})$ & $14.2(11.0-17.8)$ & $12.6(11.0-15.8)$ & $8.6(3.2-12.9)$ & $9.0(2.9-12.9)$ & $<0.0001$ \\
\hline Mean corpuscular volume (fL) & $93(67.7-101.1)$ & $89.8(77.1-100.0)$ & $88.9(59.4-119.7)$ & $92.4(71.3-101.1)$ & $<0.0001$ \\
\hline $\mathrm{MCH}(p g)$ & $31.3(21.8-35.0)$ & $30.4(24.0-33.6)$ & $29.6(16.3-43.9)$ & $30.9(19.7-36.3)$ & $<0.0001$ \\
\hline $\mathrm{MCH}$ concentration (g/dL) & $33.8(29.0-36.1)$ & $33.2(29.5-35.5)$ & $32.6(25.4-37.7)$ & $33.7(27.6-37.4)$ & $<0.0001$ \\
\hline Ret-He (pg) & $34.5(24.2-41.0)$ & $32.2(22.4-35.9)$ & $29.7(14.4-39.1)$ & $33.9(16.2-40.4)$ & $<0.0001$ \\
\hline Serum iron $(\mu \mathrm{g} / \mathrm{dL})$ & $106.0(50.0-267.0)$ & $32(4.0-242.0)$ & $27.0(2.0-245.0)$ & $82.0(50.0-489.0)$ & $<0.0001$ \\
\hline Ferritin $(\mathrm{ng} / \mathrm{mL})$ & $111.6(13.0-879.4)$ & $78.1(2.2-2,885.5)$ & $162.9(0.3-5,728.7)$ & $194.2(0.5-7,736.0)$ & 0.0043 \\
\hline Transferrin saturation (\%) & $32.9(13.8-94.7)$ & $12.8(1.2-64.7)$ & $10.9(0.9-70.8)$ & $31.5(13-119.9)$ & $<0.0001$ \\
\hline
\end{tabular}

Values are presented as median (range) or number.

Abbreviations: ID, iron deficiency; IDA, iron deficiency anemia; Hb, hemoglobin; $\mathrm{MCH}$, mean corpuscular hemoglobin; Ret-He, reticulocyte hemoglobin equivalent. 
다. 또한 건강검진센터 방문자 3,115 명 중에서 전혈구검사, 신기 능 및 간기능검사, 혈청 철 관련 검사결과가 정상인 82 명을 대조 군(control group)으로 선별하였다.

대상군은 Kruskal-Wallis test와 chi-square test를 통해 비교 하였고, $P$-value 0.05 미만을 통계적으로 유의미한 것으로 간주 하였다. 수신기작동특성곡선(receiver operation characteristic curve, ROC) 분석을 시행하여 철결핍성빈혈의 진단을 위한 망상 적혈구혈색소치의 결정치, 민감도, 특이도 및 곡선아래면적(area under the curve, AUC)을 결정하였다.

\section{결과}

분석 대상군의 나이, 성별, 혈색소, 적혈구지수 및 혈청 철 관련 지표는 Table 1에 제시하였다. 철결핍군과 철결핍성빈혈군의 망 상적혈구혈색소치는 대조군 및 비철결핍성빈혈군보다 통계적으

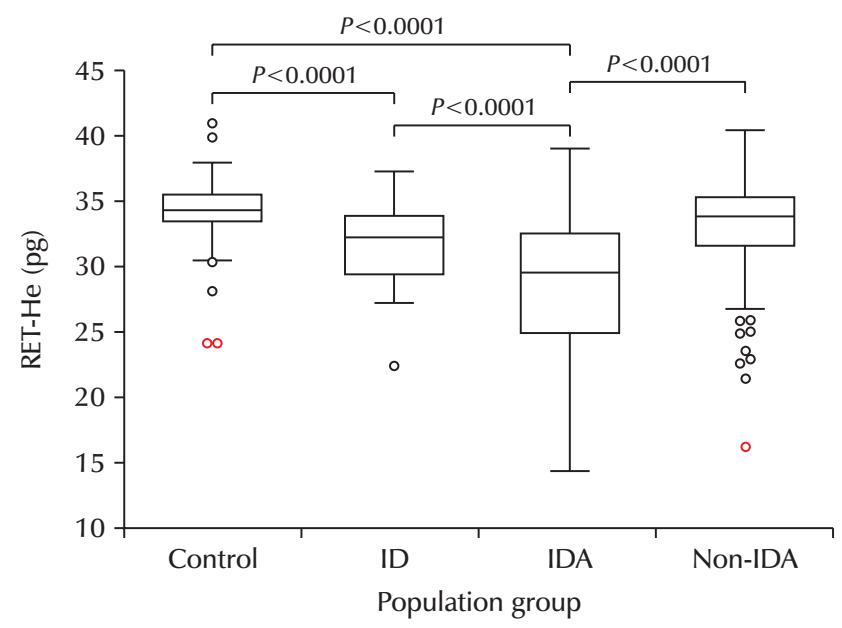

Fig. 1. Reticulocyte hemoglobin equivalent among the groups. Abbreviations: ID, iron deficiency; IDA, iron deficiency anemia; Ret$\mathrm{He}$, reticulocyte hemoglobin equivalent.
로 유의하게 낮은 값을 보였다 $(P<0.0001)$ (Fig. 1). 망상적혈구혈 색소치의 중앙값은 각각 철결핍군 $32.2 \mathrm{pg}$, 철결핍성빈혈군 29.7 $\mathrm{pg}$, 비철결핍성빈혈군 $33.9 \mathrm{pg}$, 대조군 $34.5 \mathrm{pg}$ 로 측정되었다 (Fig. 1). 철결핍군과 철결핍성빈혈군의 평균적혈구용적, 혈청 철 및 철포화백분율은 대조군과 비철결핍성빈혈군에 비해 유의하게 낮은 값을 보였다(Table 1). 또한 철결핍성빈혈군의 평균적혈구혈 색소량과 평균적혈구혈색소농도는 대조군과 비철결핍성빈혈군에 서보다 유의하게 낮은 값을 보였으며, 철결핍성빈혈군의 페리틴은 비철결핍성빈혈에 비해 유의하게 낮은 값을 보였다(Table 1).

대조군과 철결핍성빈혈군의 망상적혈구혈색소치 비교 시, 남 자는 임계치 $32.6 \mathrm{pg}$ 에서 AUC 0.881 (95\% 신뢰구간, 0.825$0.924)$, 민감도 $76 \%$, 특이도 $93 \%$, 여자는 임계치 $32.3 \mathrm{pg}$ 에서 AUC 0.830 (95\% 신뢰구간, 0.760-0.886), 민감도 75\%, 특이도 $88 \%$ 로 확인되었다(Table 2). 또한 철결핍성빈혈군과 비철결핍성 빈혈군의 망상적혈구혈색소치 비교 시, 남자는 임계치 $31.1 \mathrm{pg}$ 에 서 AUC 0.757 (95\% 신뢰구간, 0.699-0.809), 민감도 63\%, 특이 도 $82 \%$, 여자는 임계치 $31.6 \mathrm{pg}$ 에서 AUC 0.774 (95\% 신뢰구간, $0.714-0.827)$, 민감도 $71 \%$, 특이도 $75 \%$ 로 대조군과 철결핍성빈 혈군 비교 시보다 임계치의 민감도 및 특이도가 낮았다(Table 2).

\section{고찰}

망상적혈구는 골수에서 생성되어 말초혈액에서 1-2일 정도 순 환 후 적혈구로 성숙하는 세포이다. 평균수명이 120 일로 긴 적혈 구에 비해 망상적혈구는 평균 수명이 짧기 때문에, 망상적혈구혈 색소치는 다른 혈액학적 지표보다 가장 최근의 철결핍 상태를 잘 반영할 수 있다. 또한 망상적혈구혈색소치는 혈청 페리틴과 달리 감염이나 염증 등에 영향받지 않으므로 철결핍성빈혈과 만성질환 빈혈을 감별하는 데 도움이 된다. 뿐만 아니라 망상적혈구혈색소 치는 환자 간 생물학적 변이(between-patient variability)가 혈 청 페리틴보다 낮으며, 추가 시약이나 비용 없이도 망상적혈구 측

Table 2. The optimal cut-off values for the diagnosis of IDA

\begin{tabular}{clccccc}
\hline Study population & Sex & Cut-off & AUC & 95\% Cl & Sensitivity (\%) & Specificity (\%) \\
\hline IDA vs. control & Male & 32.6 & 0.881 & $0.825-0.924$ & 76 & 93 \\
& Female & 32.3 & 0.830 & $0.760-0.886$ & 75 & 88 \\
& Total & 32.3 & 0.851 & $0.809-0.888$ & 72 & 90 \\
\multirow{2}{*}{ IDA vs. non-IDA } & Male & 31.1 & 0.757 & $0.699-0.809$ & 63 & 71 \\
& Female & 31.6 & 0.774 & $0.714-0.827$ & 68 & 75 \\
& Total & 31.5 & 0.765 & $0.720-0.805$ & 68 \\
\hline
\end{tabular}

Abbreviations: AUC, area under the curve; $\mathrm{Cl}$, confidence interval; IDA, iron deficiency anemia. 
정과 더불어 2 분 이내에 자동화된 과정을 통해 간단하게 측정할 수 있는 파라미터이다[4,9,11].

본 연구에서는 철결핍성빈혈을 진단하기 위한 망상적혈구혈색 소치의 임상적 유용성을 평가하였다. 망상적혈구혈색소치는 철결 핍군과 철결핍성빈혈군에서 대조군에 비해 통계적으로 유의하게 낮게 관찰되었으며, 이는 국외에서 보고된 기존 연구결과와도 일 치한다[3]. 기존 임상검사로 사용하던 평균적혈구용적, 혈청 철, 철포화백분율도 철결핍군과 철결핍성빈혈군에서 대조군에 비해 통계적으로 유의하게 낮게 관찰되었다. 하지만 체내 저장철 결핍 을 반영한다고 알려진 페리틴은 대조군과 철결핍성빈혈군 간에 유 의한 차이가 관찰되지 않았으며, 철결핍성빈혈군의 페리틴이 오히 려 대조군에서보다 높은 경우도 관찰되었다. 본 연구의 철결핍성 빈혈군에서 감염, 염증, 만성질환 등이 동반되는 경우 페리틴이 증 가할 수 있기 때문으로 생각된다. 이런 경우 망상적혈구혈색소치 와 같은 파라미터가 페리틴의 대안이 될 수 있다.

또한 ROC 분석결과 임계치 $32.3 \mathrm{pg}$ 에서 민감도 $72 \%$, 특이 도 $90 \%$ 를 보여 철결핍성빈혈의 진단을 위한 유용한 지표로 확인 되었다. 철결핍성빈혈의 진단을 위한 망상적혈구혈색소치의 임 계치는 환자군의 특성 및 분류기준에 따라 29.0-32.4 pg (민감 도 47\%-100\%, 특이도 $75.5 \%-93.2 \%)$ 로 다양하게 보고되었다 $[4,6,9,10]$. 종양 환자들을 대상으로 시행한 연구에서는 혈색소 $11 \mathrm{~g} / \mathrm{dL}$ 미만, 철 $40 \mu \mathrm{g} / \mathrm{dL}$ 미만, 철포화백분율 $20 \%$ 미만을 충 족하는 경우 철결핍성빈혈로 정의하였고, 임계치 $32 \mathrm{pg}$ 이상일 때 철결핍성빈혈을 배제하였다. 또 다른 연구에서는 만성염증, 감 염, 만성신질환 등을 동반한 환자군에 대해 여자의 경우 혈색소 12 $\mathrm{g} / \mathrm{dL}$, 남자의 경우 혈색소 $13 \mathrm{~g} / \mathrm{dL}$ 미만, 페리틴 $15 \mathrm{ng} / \mathrm{mL}$ 미만 을 철결핍성빈혈로 정의하였고, 임계치 $30 \mathrm{pg}$ 이상에서 철결핍성 빈혈을 배제할 수 있다고 하였다[3,9]. 본 연구에서는 철결핍성빈 혈을 선별하기 위한 망상적혈구혈색소치의 임계치 $32.3 \mathrm{pg}$ 를 산 출하였고, 이는 기존 보고와 크게 다르지 않은 것으로 확인되었다
$[3,4,6,9,10]$.

본 연구에서는 전혈구검사 및 혈청 철 관련 지표 검사를 시행한 환자들의 검사실적 소견을 후향적으로 리뷰하여 환자군을 분류하 였다. 그러나 철결핍 환자군 분류를 위해 사용한 지표 중 혈청 철, 페리틴, 총 철결합능 및철포화백분율 검사를 모두 시행한 경우가 드물었다. 기존 연구에서는 철결핍 상태를 정의하기 위해 페리틴 또는 혈청 철을 단독으로 사용하거나 여러 지표를 조합하여 분류 하였다[3,8,9]. 본 연구에서는 분류 오류를 최소화하기 위해 최소 2 개 이상의 지표를 조합하여 철결핍 상태를 정의하였다. 그러나 임상진단명, 염증에 대한 지표 등을 확인하지 못하였으며 철결핍 성빈혈과 만성질환빈혈의 동반되는 경우 등을 고려하지 못하여 본 연구결과를 일반화하기에 한계가 있다.

본 연구는 국내에서 처음으로 철결핍성빈혈 진단에 있어 망상 적혈구혈색소치의 임상적 유용성을 확인하고, 임계치를 제시하였 다는 점에 의의가 있다. 본 연구를 통해 국내에서 철결핍성빈혈 진 단을 위한 망상적혈구혈색소치의 임상검사 도입 유용성을 확인하 였다. 추후 철결핍성빈혈의 진단 알고리즘에 망상적혈구혈색소치 를 통합하기 위해 전향적인 대규모 임상연구를 통해 임상적 유용 성을 검증하고, 잘 정의된 참고집단에서 망상적혈구혈색소치의 참 고치를 설정할 필요가 있다.

\section{감사의 글}

이 연구는 대한임상검사정도관리협회의 2021년도 학술연구과 제 연구비 지원으로 수행되었다(과제번호: 2021-10).

\section{ORCID}

Kyoung-Jin Park https://orcid.org/0000-0002-1262-6815

Moon Jung Kim https://orcid.org/0000-0003-4148-9116

\section{REFERENCES}

1. Lopez A, Cacoub P, Macdougall IC, Peyrin-Biroulet L. Iron deficiency anaemia. Lancet 2016;387:907-16.

2. Mast AE, Blinder MA, Lu Q, Flax S, Dietzen DJ. Clinical utility of the reticulocyte hemoglobin content in the diagnosis of iron deficiency. Blood 2002;99:1489-91.

3. Chinudomwong P, Binyasing A, Trongsakul R, Paisooksantivatana K. Diagnostic performance of reticulocyte hemoglobin equivalent in assessing the iron status. J Clin Lab Anal 2020;34:e23225.

4. Ogawa C, Tsuchiya K, Maeda K. Reticulocyte hemoglobin content. Clin Chim Acta 2020;504:138-45.

5. Tantawy AA, Ragab IA, Ismail EA, Ebeid FSE, Al-Bshkar RM. Reticulocyte hemoglobin content (Ret He): a simple tool for evaluation of iron status in childhood cancer. J Pediatr Hematol Oncol 2020;42:e147-51.

6. Zhang HD, Cai J, Wu M, Ren J, Du YL, Long ZB, et al. Verification of the cut-off value of the reticulocyte hemoglobin 
content to diagnose iron deficiency. Biomed Environ Sci 2020;33:543-6.

7. Urrechaga E, Borque L, Escanero JF. Erythrocyte and reticulocyte indices in the assessment of erythropoiesis activity and iron availability. Int J Lab Hematol 2013;35:144-9.

8. Toki Y, Ikuta K, Kawahara Y, Niizeki N, Kon M, Enomoto M, et al. Reticulocyte hemoglobin equivalent as a potential marker for diagnosis of iron deficiency. Int J Hematol 2017;106:116-25.

9. Peerschke El, Pessin MS, Maslak P. Using the hemoglobin content of reticulocytes (RET-He) to evaluate anemia in patients with cancer. Am J Clin Pathol 2014;142:506-12.

10. Buttarello M, Pajola R, Novello E, Rebeschini M, Cantaro S, Oliosi F, et al. Diagnosis of iron deficiency in patients undergoing hemodialysis. Am J Clin Pathol 2010;133:949-54.

11. Van Wyck DB, Alcorn H Jr, Gupta R. Analytical and biological variation in measures of anemia and iron status in patients treated with maintenance hemodialysis. Am J Kidney Dis 2010;56:540-6. 